\title{
Disomic Segregation of Microsatellites in the Tetraploid Prunus serotina Ehrh. (Rosaceae)
}

\author{
Marie C. Pairon' ${ }^{1}$ and Anne-L. Jacquemart \\ Unité d'Ecologie et de Biogéographie, Université Catholique de Louvain, Croix du Sud 4-5, B-1348 \\ Louvain-la-Neuve, Belgium
}

AdDITIONAL INDEX WORDS. polyploid, black cherry, inheritance, simple sequence repeat, allotetraploid

\begin{abstract}
Tetraploid black cherry (Prunus serotina) is the only Prunus L. species that has commercial importance as a timber tree in North America and is well known in Europe for its invasive behavior. Inheritance studies have never been performed and it is not known whether the species is allo or autotetraploid. Six microsatellite nuclear markers were used to test the inheritance in progenies of controlled crosses. Inheritance was proven to be disomic at all loci and a typical diploid mendelian inheritance was found at two loci. A first screening of a population in the invasive range showed high number of alleles per locus (ranging from 6 to 16) and high level of observed heterozygosity $(0.75$ to 1$)$. Knowing that inheritance is disomic at six microsatellite loci and that at least two of them can be treated as codominant, diploid markers will be beneficial for future genetic studies.
\end{abstract}

The genus Prunus (Rosaceae: Amygdaloideae) consists of $\approx 400$ species of trees and shrubs (Maynard et al., 1991). Many species and cultivars are grown for their edible fruits or for ornamental purposes (Rehder, 1940; Tutin et al., 1968). Several ploidy levels are found within the genus, including diploid $(2 \mathrm{n}=16$; e.g., $P$. avium L.), tetraploid $(2 \mathrm{n}=32$; e.g., P. serotina), hexaploid $(2 \mathrm{n}=$ 48; e.g., P. domestica L.), and octoploid $(2 \mathrm{n}=64 ;$ P. lusitanica L.) (Rehder, 1940; Tutin et al., 1968). Among these species, the tetraploid black cherry ( $P$. serotina) is native to North America and has been introduced in Europe. It is the only Prunus species that has commercial importance as a timber tree in its native range and its regeneration and sylvicultural characteristics have, therefore, been widely studied (Fowels, 1965; Husch, 1954; Maynard et al., 1991). During the last decades, its invasive behavior in its introduced range has become cause for concern because exotic invasives represent one of the greatest threats to species and habitat diversity (Wilcove et al., 1998).

Molecular markers are powerful tools that may help in this context to understand the mechanisms behind ongoing invasions. Among genetic markers, microsatellites have become valuable in population genetics studies because they present extremely high levels of polymorphism together with codominant inheritance (Powell et al., 1996). They have already been broadly used in Prunus for analysis of plant genetic diversity (Dirlewanger et al., 2002; Downey and Iezzoni, 2000; Hormaza, 2002), population structure (Saltonstall, 2003), seed dispersal patterns (Godoy and Jordano, 2001; Schueler et al., 2003), genetic linkage (Aranzana et al., 2003), molecular mapping (Decroocq et al., 2004), and cultivar certification (Aranzana et al., 2002; Schueler et al., 2003).

Microsatellites flanking regions are well conserved across Prunus species (Hormaza, 2002; Wünsch and Hormaza, 2002) and four microsatellite primer pairs, developed from peach $[P$. persica (L.) Batsch], sour cherry (P. cerasus L.), and sweet cherry

Received for publication 24 Dec. 2004. Accepted for publication 7 Mar. 2005 We would like to thank the Fonds Spéciaux de Recherche (FSR) of the Université Catholique de Louvain (UCL) and the Belgian federal Office for Scientific, Technical and Cultural affairs (OSTC-InPlanBel) for financial support. We thank Olivier Hardy for fruitful discussions and Olivier Raspé for revision of previous versions of this manuscript. Marie Pairon is research fellow of the Belgian National Fund of Scientific Research and Anne-Laure Jacquemart is research associate in the same institution.

${ }^{1}$ Corresponding author: E-mail address: pairon@ecol.ucl.ac.be
(P. avium), have already been used in black cherry by Downey and Iezzoni (2000) for characterizing genetic diversity of 66 accessions from Michigan, Ecuador, and Mexico.

However, interpretation of banding patterns of these markers is hindered by the polyploid nature of the species and more specifically by the lack of knowledge on the mode of inheritance (disomic or tetrasomic). Disomic inheritance is observed when only one single arrangement of bivalent pairing is created at meiosis. In this case, a tetraploid can be seen as an association of two independently segregating genomes and segregation is similar to that of nonhomologous pairs of chromosomes in diploids (Bever and Felber, 1992). In contrast, inheritance is tetrasomic if there is random pairing among the four chromosomes. Because of possible tetravalent formation and crossing over, double reduction can occur, which increases the proportion of homozygous gametes as compared to what is expected under random chromosomes segregation (Ronfort et al., 1998). Because those two different patterns have different implications for gamete formation and allele proportions, inheritance pattern has to be determined at each studied locus to correctly analyze the data. This can be done by performing controlled crosses between parents of known genotypes and analyzing progeny genotypes.

Traditionally, polyploids are divided into allopolyploids and autopolyploids on the basis of their presumed origin. Allopolyploids are formed by hybridization and subsequent chromosome doubling, whereas autopolyploids arise within a species from the chromosome doubling of the same genome (Bennett, 2004; Ronfort et al., 1998). It has often been said that allopolyploids segregate disomically, for they present two sets of homeologous chromosomes (chromosomes that are homologous, but coming from different species) that are unlikely to pair at meiosis, and autotetraploids polysomically because their chromosomes pair at random and form multivalents at meiosis (Chenuil et al., 1999; Stebbins, 1947; Wolf et al., 1989). Nevertheless, this is not always true notably because 1) reestablishment of disomic inheritance in ancient autopolyploids can occur to avoid meiotic problems (Dewet, 1979), and 2) allopolyploidy can lead to multisomic inheritance if the species originates from closely related species that may have chromosomes partly homologous to each other (Stebbins, 1950).

Because it is not known whether black cherry is allotetraploid or autotetraploid, we undertook this study to determine 
the inheritance at polymorphic microsatellite nuclear loci in diagnostic crosses.

\section{Material and Methods}

In order to choose the best crosses to carry out, a first screening of 20 potential parents in a population has been performed. The population is situated in an abandoned sand query in Belgium (lat. $50^{\circ} 41^{\prime} 18^{\prime} \mathrm{N}$, long. $4^{\circ} 43^{\prime} 33^{\prime} \mathrm{E}$ ). Several twigs bearing dormant buds were collected in early Mar. 2004 on these trees. The bud scales were removed and total DNA was extracted from 7 to 14 winter buds per tree (representing $30-80 \mathrm{mg}$ of fresh material) following a CTAB protocol (Doyle and Doyle, 1990).

Eight microsatellite nuclear primer pairs were used to amplify template DNA. Four of them (PceGA34, Ps12a02, pchpgms3, pchgms2) had already been tested on black cherry (Downey and Iezzoni, 2000), while the four remaining (M2b, M4c, M12a, and M15a) had been developed from a peach fruit cDNA library by Yamamoto et al. (2002). Forward primers were fluorescently labeled with either 6-FAM or HEX (Eurogentec S.A., Seraing, Belgium). Polymerase chain reaction conditions were slightly modified from the original conditions described both by Downey and Iezzoni (2000) and by Yamamoto et al. (2002). Diluted template DNA (15 $\mathrm{ng}$ ) was amplified in $15 \mu \mathrm{L}$ reaction mixture containing $2.5 \mathrm{~mm} \mathrm{MgCl}, 0.2 \mathrm{mg} \cdot \mathrm{mL}^{-1}$ of BSA, $0.1 \mathrm{~mm}$ of each $\mathrm{dNTP}, 0.5 \mu \mathrm{M}$ of each primer, $0.6 \mathrm{U}$ of Taq DNA polymerase (Roche Diagnostics, Basel, Switzerland), and 1.5 $\mu \mathrm{L}$ of the Taq buffer. PCR reactions were performed in thermocyclers (models 2400 and 9700; Perkin Elmer Life and Analytical Sciences, Boston), using one step of $4 \mathrm{~min}$ at $94{ }^{\circ} \mathrm{C}, 35$ cycles of $25 \mathrm{~s}$ at $94{ }^{\circ} \mathrm{C}, 45 \mathrm{~s}$ at annealing temperature (depending on the primer, see Table 1 ), and $45 \mathrm{~s}$ at $72^{\circ} \mathrm{C}$, followed by one final elongation step of $7 \mathrm{~min}$ at $72^{\circ} \mathrm{C}$. Amplified PCR products were then sized using an ABI 3100 sequencer (Applied Biosystems, Foster City, Calif.). Genescan 400HD was used as the internal size standard and data were analyzed using GeneMapper software version 3.0 (Applied Biosystems).

Six different individuals were chosen as parents for three controlled crosses on the basis of the alleles they presented at different loci. Parents of one cross were chosen for testing inheritance at a given locus when they shared no or a minimum number of alleles at that locus. Crosses were carried out in June 2004. On each tree that was used as pollen receiver (maternal parent), five to 10 twigs, each bearing from five up to 13 inflorescences, were enclosed in nylon mesh bags prior to anthesis in order to exclude pollinators. A wire frame was placed on the twig to keep the bag from collapsing and interfering with the floral development. For each cross, stamens were collected on the tree that served as pollen donor (paternal parent) and brushed several times across the stigmas of mature opened flowers of the maternal parent until visible deposit of pollen was observed. A flower was considered as mature when its stigma was pale green and sticky in the center with a cream-colored periphery, as described by Stairs and Hauck (1968). Emasculation of the flowers was not necessary since the species is self-incompatible (Stairs and Hauck, 1968). The bags were removed when every single stigma had taken a brownish color, showing that it was no longer receptive.

Fruits were collected unripe to prevent them from falling and from being eaten by birds. Embryos were extracted from the woody endocarp and stored at $-80{ }^{\circ} \mathrm{C}$ until DNA isolation. Because embryo DNA was not successfully extracted following the CTAB protocol used for buds, total DNA was isolated following a procedure adapted from Cheung et al. (1993). Two major modifications were made: 1) after crushing the embryo in 320 $\mu \mathrm{L}$ of buffer (200 mм Tris-HCl, $70 \mathrm{~mm}$ EDTA, $2 \mathrm{M} \mathrm{NaCl}, 20 \mathrm{~mm}$ sodium bisulfite) and $80 \mu \mathrm{L}$ of sarcosyl, $16 \mu \mathrm{g}$ of proteinase $\mathrm{K}$ was added, and 2) solution was kept for 1 to $2 \mathrm{~h}$ at $-20{ }^{\circ} \mathrm{C}$ after addition of cold isopropanol. Microsatellite PCR amplification and allele sizing were carried out following the protocol described above for parents.

\section{Data analyses}

Gamete genotypes ratios were deduced from progeny genotypes for all loci whenever crosses involved parents that shared one or no alleles at a given locus.

Chi-square goodness-of-fit analysis tests were performed to determine which hypotheses described best the observed frequencies. When there was only $1 \mathrm{df}$, values were corrected for continuity. When it was not possible to find parents sharing less than two alleles at a given locus, gamete genotypes could not be inferred from progeny phenotypes. In this particular case, chi-square tests could not be used since they are less accurate when sample sizes are small. Instead, bayesian tests, as defined by Olson (1997) for inheritance studies were computed. Bayesian probabilities can be interpreted as the "confidence in an individual having a particular underlying segregation ratio" or as the "degree to which the data support one hypothesis over another" (Olson, 1997).

Table 1. Characteristics of the six microsatellite loci used to infer the allelic segregation of the tetraploid Prunus serotina. Locus codes are the same as those used in the studies that first described the primer pairs. Annealing temperatures have been slightly modified from those described originally and adjusted temperatures used in this study are shown. Allele size range in base pairs (bp), maximum number of alleles per sample, total number of alleles, and observerd heterozygosity (Ho) have been obtained after analysis of a Belgian population of 20 individuals.

\begin{tabular}{lcccccc}
\hline $\begin{array}{l}\text { Locus } \\
\text { code }\end{array}$ & $\begin{array}{c}\text { Annealing } \\
\text { temp }\left({ }^{\circ} \mathrm{C}\right)\end{array}$ & $\begin{array}{c}\text { Allele size } \\
\text { range (bp) }\end{array}$ & $\begin{array}{c}\text { Maximum alleles } \\
\text { per sample (no.) }\end{array}$ & $\begin{array}{c}\text { Total } \\
\text { alleles (no.) }\end{array}$ & Ho $^{z}$ & Gene diversity $^{-}$ \\
\hline pchpgms3 $^{y}$ & 60 & $182-232$ & 4 & 16 & 1 & 0,877 \\
M4c $^{\mathrm{x}}$ & 60 & $65-89$ & 4 & 11 & 1 & 0,857 \\
M12a $^{\mathrm{x}}$ & 56 & $170-216$ & 4 & 14 & 0.95 & 0,906 \\
pchgms2 $^{\mathrm{y}}$ & 60 & $130-154$ & 2 & 6 & 0.75 & 0,658 \\
PceGA34 & 60 & $136-162$ & 2 & 6 & 0.85 & 0,791 \\
Ps12a02 & 56 & $146-168$ & 4 & & 1 & 0,868 \\
\hline
\end{tabular}

${ }^{\mathrm{z}}$ Proportion of individuals displaying a multiallelic phenotype.

${ }^{\mathrm{y}}$ Downey and Iezzoni (2000).

${ }^{\mathrm{x}}$ Yamamoto et al. (2002). 
Table 2. Phenotypes of the six black cherry individuals chosen as parent trees in the controlled crosses performed to determine allelic segregation at six microsatellite loci. Allele sizes are given for the loci considered. Individuals used as pollen receivers (maternal parents) are in italic as well as the alleles typical of these maternal parents. Individuals used as pollen donors (paternal parents) are underscored as well as the alleles typical of these paternal parents. Alleles in bold are those shared by both pollen donors and pollen receivers. The three crosses that were performed are: $9 * \underline{19}$, $11 * \underline{16}$ and $15 * 1$.

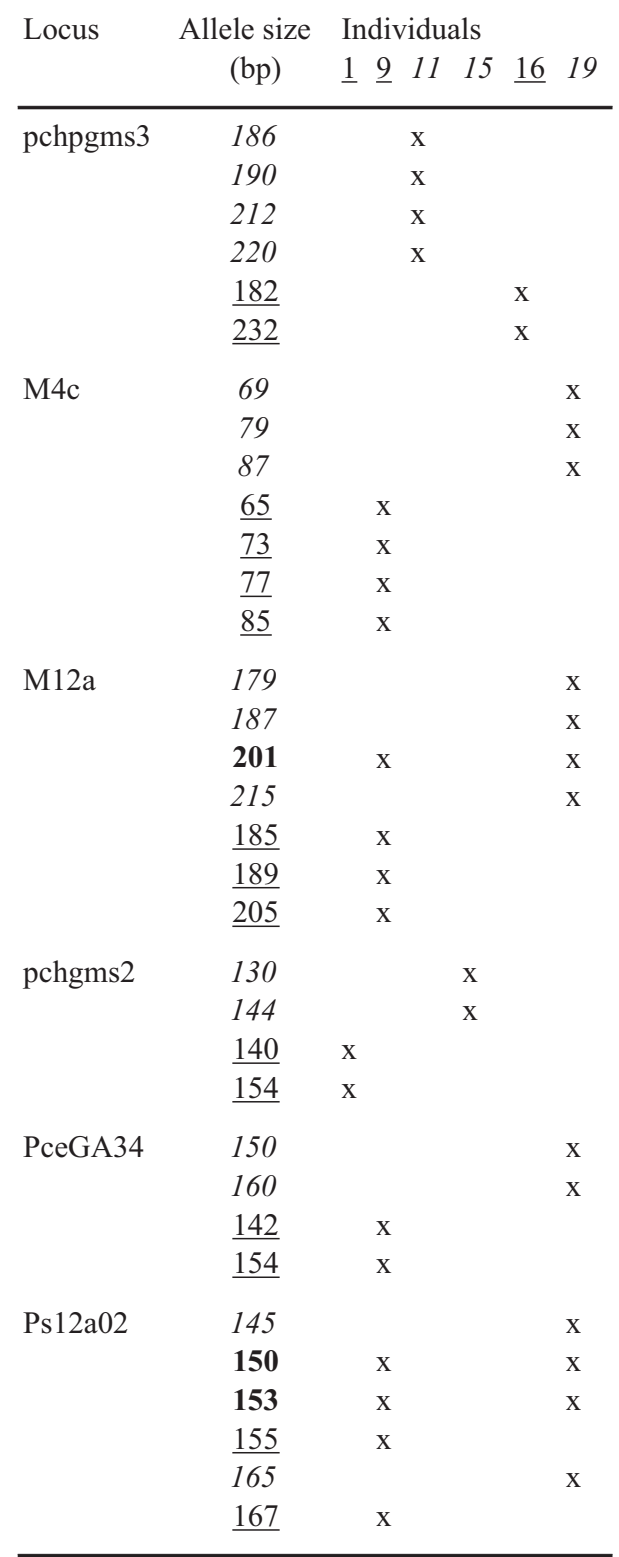

Linkage between loci was tested using a chi-square test of independence when the same seeds were used to test inheritance at different loci. Analysis was run using Proc FREQ on SAS for Windows release 8.2 (SAS Institute, Cary, N.C.).

The data obtained from preliminary screening of the population were used to estimate the genetic diversity within this population. Polymorphism at each locus was characterized by the total number of alleles found in the population. Allelic frequencies and expected heterozygosities could not be calculated as they can in diploid species because $P$. serotina is tetraploid and the allele dosage could not be determined. Therefore, only observed heterozygosity, computed as the proportion of individuals displaying a heterozygotic allele phenotype at a locus, was computed.

\section{Results}

As expected, the four primer pairs described by Downey and Iezzoni (2000) successfully amplified black cherry DNA. Of the four primer pairs developed by Yamamoto et al. (2002) on peach, two provided polymorphic patterns (M4c and M12a), one failed to amplify (M15a), and one gave aspecific amplification (M2b). The two latter primer pairs were therefore not used for further analysis. Inheritance of the six markers that gave polymorphism was tested using controlled crosses. As far as it was possible, parents crossed had one or no allele in common, allowing to determine gamete genotypes from progeny genotypes and to perform chi-square goodness of fit tests on gamete genotypes rather than on progeny genotypes. Parents crossed for testing inheritance shared no allele at loci pchgms3, M4c, PceGA34, and pchgms2; one allele at locus M12a; and, unfortunately, two alleles at locus ps12a02 (Table 2). It was possible to infer gamete genotypes at locus M12a because both parents were full heterozygotes (each presenting four alleles). On the contrary, it was not possible to infer the gametes genotype proportions from the progenies genotypes at locus ps $12 \mathrm{a} 02$ and the inheritance at that locus will thus be tested differently with Bayesian probablities.

At the five loci sharing one or no allele, gamete proportions were used for testing inheritance.

In order to test which inheritance hypothesis best fitted the observed gamete proportions, expected gamete genotypes ratios are presented in Table 3 . Three different parental types are defined, corresponding to individuals presenting four, three and two peaks. All possible parent genotypes are considered for parents presenting three and two peaks. For each parent genotype, there is more than one disomic mating possibility, depending upon how the markers are associated within the two pairs of homeologous chromosomes. Proportions under tetrasomic hypothesis are calculated under the assumption that no double reduction occurred.

Table 4 gives the gamete genotypes, observed proportions and results of chi-square tests for tetrasomic and disomic hypotheses. At all five loci, tetrasomic inheritance was rejected. Loci pchpgms2 and PceGA34 showed nevertheless a particular pattern of segregation. At these two loci, each parent has only homozygous gametes, which would only be expected if parents had diploid genotypes ( $h i$ ) and if segregation was mendelian diploid.

Inheritance at locus ps $12 \mathrm{a} 02$ had to be tested using progeny genotypes instead of gamete genotypes because parents used to test the inheritance at that locus shared two alleles (see Table 2 ). Because of the high number of expected genotypes (28 and 16 for the tetrasomic and disomic hypothesis, respectively), the expected proportions are not shown and chi-square tests were not used since they are less accurate when sample size are small 
Table 3. Theoretical expected gamete ratio of a tetraploid species such as the species under study, Prunus serotina, under tetrasomic and disomic inheritances. Three parental phenotypes (parental type 1 to 3 ) that can be encountered in a tetraploid organism are taken into account. The fourth phenotype (i.e., the homozygote ' $J$ ') is not shown because it gives only homozygous gametes ('jj'). All different parental genotypes are considered for each tetraploid phenotype. Expected gamete ratios under tetrasomic and disomic allelic segregation hypotheses are given. For the disomic inheritance hypothesis, all possible pairing of homeologous chromosomes are considered.

\begin{tabular}{|c|c|c|c|c|c|}
\hline \multirow[b]{2}{*}{$\begin{array}{l}\text { Parental } \\
\text { type }\end{array}$} & \multirow[b]{2}{*}{$\begin{array}{l}\text { Parental } \\
\text { phenotype }\end{array}$} & \multirow[b]{2}{*}{$\begin{array}{l}\text { Parental } \\
\text { genotype }\end{array}$} & \multirow{2}{*}{$\begin{array}{l}\text { Tetrasomic } \\
\text { Expected gamete } \\
\text { ratio }\end{array}$} & \multicolumn{2}{|c|}{ Disomic } \\
\hline & & & & $\begin{array}{l}\text { Possible homeologous } \\
\text { chromosomes pairing }\end{array}$ & $\begin{array}{l}\text { Expected gamete } \\
\text { ratio }\end{array}$ \\
\hline 1 & $\mathrm{ABCD}$ & abcd & 1ac:1ad:1bc:1bd:1ab:1cd & $\begin{array}{l}(\mathrm{ab})(\mathrm{cd}) \\
(\mathrm{ad})(\mathrm{bc}) \\
(\mathrm{ac})(\mathrm{bd})\end{array}$ & $\begin{array}{l}\text { 1ac:1ad:1bc:1bd } \\
1 \mathrm{ac}: 1 \mathrm{bd}: 1 \mathrm{ab}: 1 \mathrm{~cd} \\
1 \mathrm{ad}: 1 \mathrm{bc}: 1 \mathrm{ab}: 1 \mathrm{~cd}\end{array}$ \\
\hline 2 & EFG & $\begin{array}{l}\text { eefg } \\
\text { effg } \\
\text { efgg }\end{array}$ & $\begin{array}{l}\text { 1ee:2ef:2eg:1fg } \\
\text { 1ff:2ef:1eg:2fg } \\
\text { 1gg:1ef:2eg:2fg }\end{array}$ & $\begin{array}{l}\text { (ee)(fg) } \\
(\mathrm{ef})(\mathrm{eg}) \\
(\mathrm{ff})(\mathrm{eg}) \\
(\mathrm{ef})(\mathrm{fg}) \\
(\mathrm{ef})(\mathrm{gg}) \\
(\mathrm{eg})(\mathrm{fg})\end{array}$ & $\begin{array}{l}\text { 1ef:1 eg } \\
\text { lee:1ef:1eg: } 1 \mathrm{fg} \\
1 \mathrm{ef}: 1 \mathrm{fg} \\
1 \mathrm{ff}: 1 \mathrm{ef}: 1 \mathrm{eg}: 1 \mathrm{fg} \\
1 \mathrm{eg}: 1 \mathrm{fg} \\
1 \mathrm{gg}: 1 \mathrm{ef}: 1 \mathrm{eg}: 1 \mathrm{fg}\end{array}$ \\
\hline 3 & $\mathrm{HI}$ & $\begin{array}{l}\text { hhii } \\
\text { hhhi } \\
\text { hiii }\end{array}$ & $\begin{array}{l}\text { 1hh:4hi:1ii } \\
\text { 1hh:1hi } \\
\text { 1hi:1ii }\end{array}$ & $\begin{array}{l}\text { (hh)(ii) } \\
\text { (hi)(hi) } \\
\text { (hh)(hi) } \\
\text { (hi)(ii) }\end{array}$ & $\begin{array}{l}\text { 1hi } \\
\text { 1hh:2hi:1ii } \\
\text { 1hh:1hi } \\
\text { 1hi:1ii }\end{array}$ \\
\hline & & hi & - & (hi) & $1 \mathrm{i}: 1 \mathrm{~h}$ \\
\hline
\end{tabular}

Table 4. Inheritance analysis results at five Prunus serotina microsatellite loci. A parental type is assigned to each parent on the basis of its allele number according to the convention used in Table 3. Observed gamete genotypes are compared to the possible expected gamete ratios described in Table 3 under different parental genotypes and possible homeologous pairing. Chi-square values and corresponding $P$ values are given. Nonsignificant chi-square values and corresponding hypothesis are highlighted.

\begin{tabular}{|c|c|c|c|c|c|c|c|c|c|}
\hline \multirow[b]{2}{*}{ Locus $^{2}$} & \multirow[b]{2}{*}{ Parenty } & \multirow[b]{2}{*}{$\begin{array}{l}\text { Parental } \\
\text { type }^{x}\end{array}$} & \multirow[b]{2}{*}{$\begin{array}{l}\text { Observed gamete } \\
\text { genotypes }^{\mathrm{w}}\end{array}$} & \multicolumn{3}{|c|}{ Tetrasomic } & \multicolumn{3}{|c|}{ Disomic } \\
\hline & & & & $\begin{array}{l}\text { Parental } \\
\text { genotype } \\
\text { tested }^{\mathrm{x}}\end{array}$ & $\chi^{2}$ & $P$ & $\begin{array}{l}\text { Possible } \\
\text { chromosome } \\
\text { pairing }{ }^{x}\end{array}$ & $\chi^{2}$ & $P$ \\
\hline \multirow[t]{2}{*}{ pchpgms 3} & 11 & 1 & 10ac:8ad:16bc:14bd & abcd & 29 & $<0.0001$ & $(a b)(c d)$ & 3.33 & 0.34 \\
\hline & $\underline{16}$ & 3 & $47 \mathrm{hi}$ & $\begin{array}{l}\text { hhii } \\
\text { hhhi, hiii }\end{array}$ & $\begin{array}{l}23.5 \\
45.02\end{array}$ & $\begin{array}{l}<0.0001 \\
<0.0001\end{array}$ & (hh)(ii) & 0 & 1 \\
\hline \multirow[t]{2}{*}{ M4c } & 9 & 1 & $9 \mathrm{ac}: 11 \mathrm{ad}: 6 \mathrm{bc}: 10 \mathrm{bd}$ & abcd & 20.33 & 0.0011 & $(a b)(c d)$ & 3.4 & 0.33 \\
\hline & $\underline{19}$ & 2 & $20 \mathrm{ef}: 16 \mathrm{eg}$ & $\begin{array}{l}\text { eefg } \\
\text { effg } \\
\text { efgg }\end{array}$ & $\begin{array}{l}18.67 \\
40 \\
52\end{array}$ & $\begin{array}{l}0.0003 \\
<0.0001 \\
<0.0001\end{array}$ & $(\mathrm{ee})(\mathrm{fg})$ & 0.26 & 0.61 \\
\hline \multirow[t]{2}{*}{ M12a } & 9 & 1 & 8ac:6ad:12bc:9bd & abcd & 20.71 & 0.0009 & $(a b)(c d)$ & 2.14 & 0.54 \\
\hline & $\underline{19}$ & 1 & 10ad:7bc:6ad:12cd & abcd & 21.4 & 0.0007 & (ac)(bd) & 2.6 & 0.46 \\
\hline \multirow[t]{2}{*}{ pchgms 2} & 15 & 3 & $17 \mathrm{~h}: 22 \mathrm{i}$ & hhii & 79.92 & $<0.0001$ & $\begin{array}{l}\text { (hi)(hi) } \\
\text { (hi) }\end{array}$ & $\begin{array}{l}41.51 \\
0.42\end{array}$ & $\begin{array}{l}<0.0001 \\
0.52\end{array}$ \\
\hline & $\underline{1}$ & 3 & $23 \mathrm{~h}: 16 \mathrm{i}$ & hhii & 87.77 & $<0.0001$ & $\begin{array}{l}\text { (hi)(hi) } \\
\text { (hi) }\end{array}$ & $\begin{array}{l}40.28 \\
0.92\end{array}$ & $\begin{array}{l}<0.0001 \\
0.34\end{array}$ \\
\hline \multirow[t]{2}{*}{ PceGA34 } & 9 & 3 & $16 \mathrm{~h}: 17 \mathrm{i}$ & hhii & 66.09 & $<0.0001$ & $\begin{array}{l}\text { (hi)(hi) } \\
\text { (hi) }\end{array}$ & $\begin{array}{l}33.06 \\
0\end{array}$ & $\begin{array}{l}<0.0001 \\
1\end{array}$ \\
\hline & $\underline{19}$ & 3 & $13 \mathrm{~h}: 20 \mathrm{i}$ & hhii & 70.45 & $<0.0001$ & $\begin{array}{l}\text { (hi)(hi) } \\
\text { (hi) }\end{array}$ & $\begin{array}{l}35.97 \\
1.10\end{array}$ & $\begin{array}{l}<0.0001 \\
0.29\end{array}$ \\
\hline
\end{tabular}

${ }_{\mathrm{z}}^{\mathrm{L}}$ ocus ps12a02 is not shown in the table because the cross used to test inheritance at that locus involved parents sharing two alleles and it was therefore not possible to find gamete genotypes. Progeny genotypes were used instead.

${ }^{\mathrm{y}}$ Maternal parents are in italic and paternal parents are underscored.

${ }^{\mathrm{x}}$ Parental type, parental genotype and chromosome pairing are as defined in Table 3 .

${ }^{\mathrm{w}}$ Letters are given to alleles so that the smallest size corresponds to the first letter in alphabetical order, e.g., for individual 11 at locus $\mathrm{S} 3, \mathrm{a}=186, \mathrm{~b}=190, \mathrm{c}=212$ and $\mathrm{d}=220$. See Table 2 for parent allele sizes. 
(here to test two hypotheses, a minimum of 140 seeds should have been genotyped). Instead, Bayesian tests were computed following the procedure described by Olson (1997). Bayesian probability of fitting disomic inheritance was 0.99 in comparison with the probability of $5.57 \mathrm{e}-08$ to fit the tetrasomic hypothesis. This shows strong discrimination in favor of disomic inheritance at locus ps $12 \mathrm{a} 02$.

Linkage between loci was checked when the progenies of a same cross were used to test the inheritance at more than one locus. This is only the case for one cross that has been used to test inheritance at loci M12, M4, PceGA34, and ps12a02. Tests were nonsignificant with $P$ values ranging from 0.26 to 0.89 , showing no rejection of the null hypothesis of no linkage between loci. Therefore, none of these loci were linked to one another.

Within the screened population, all six loci were extremely polymorphic with the number of alleles per locus ranging from 6 to 16 (mean number of 10.33). Observed heterozygosity ranged from 0.75 to 1 (Table 1 ).

\section{Discussion}

Of the six primer pairs used in this study, four had already been used in black cherry by Downey and Iezzoni (2000) and two had been described by Yamamoto et al. (2002) on peach. The two latter primer pairs gave polymorphism, showing again the conservation of microsatellite flanking regions within the genus Prunus (Hormaza, 2002; Wünsch and Hormaza, 2002).

Controlled crosses were carried out to determine whether the studied loci segregate tetrasomically or disomically. The six microsatellite nuclear loci considered segregate disomically. This means that the four chromosomes do not pair randomly at meiosis and that gametes are formed by segregation of two independent sets of homeologous chromosomes, at least at the six loci investigated. This is consistent with the reproductive cytology analysis done on black cherry by Stairs and Hauck (1968), who found only bivalent pairing of chromosomes and represents good arguments in favor of the allotetraploid origin of black cherry.

A particular pattern was observed at loci PceGA34 and pchpgms 2 where a maximum of two alleles was found for both parents and progenies. Phenotypic classes were those that would be expected from diploid segregation. Downey and Iezzoni (2000) also found a maximum of two alleles per individual at these two loci for 66 accessions sampled within the native range. This can be explained either by the fact that these two loci were initially only present in one of the ancestral "progenitor species" or by the fact that one of the two sets of homeologous chromosomes had undergone a mutation at these loci. The second hypothesis can be viewed as a particular case of gene silencing that has been widely described for isozyme loci (see Soltis and Soltis, 1993 for review). Because duplicated genes are present in polyploids, the relaxation of selection on one gene copy allows divergence between the duplicated genes, which could lead in some cases to a loss or inactivation of one of the loci. If this process occurs for a long time, the number of genes expressed in a polyploid could be sufficiently reduced to return the polyploid level of expression similar or identical to that of the diploid ancestor. A genetically diploidized genome has been described at microsatellite loci in the octoploid Fragaria virginiana Mill. where all loci showed a diploid pattern of inheritance (Ashley et al., 2003). In black cherry, four alleles are still present at four of the six loci under study. Therefore, there is no evidence that would lead to support the gene silencing hypothesis against the hypothesis that two loci never existed in one of the ancestor species.
The supposed allotetraploid origin of the species raises question of what the potential parental lineages might have been. Existing phylogenies of Prunus classify the species in a complex of two and sometime three intermingled subgenera (Laurocerasus Roem., Padus Borckh., and Cerasus Pers.) (Bortiri et al., 2001; Lee and Wen, 2001; Shaw and Small, 2004). Unfortunately, because only a few species of these subgenera were sampled, there is not enough information to correctly infer parental origins.

In order to characterize the polymorphism and heterozygosity of the six markers used, a first screening of twenty individuals in the population where the crosses were performed has been realized. Total number of alleles per locus (A) is high with a mean of 10.33. Observed heterozygosity (Ho) was also high, especially when excluding the two loci showing a maximum of two alleles per individual (mean after exclusion 0.987). Values are rather similar to those given for the allotetraploid sour cherry $(\mathrm{A}=10.7$ and mean Ho = 0.987) (Cantini et al., 2001). High number of alleles and observed heterozygosity are expected in tetraploids and particularly in allotetraploids because of their two sets of homeologous chromosomes. This fixed heterozygosity of allopolyploids has often been accounted to be an important cause of their evolutionary success (Ramsey and Schemske, 2002) and may partly explain the adaptation abilities of black cherry in its introduced range.

Means calculated at the two loci that gave a maximum of two alleles per individual $(\mathrm{A}=7.5$ and $\mathrm{Ho}=0.8)$ are similar or higher to values given for other cultivated diploid Prunus species as sweet cherry $[\mathrm{A}=2.6$ to 6 and $\mathrm{Ho}=0.50$ to 0.66 (Clarke and Tobutt, 2003; Dirlewanger et al., 2002; Schueler et al., 2003)], peach $[\mathrm{A}=3.20$ and 4.20 and $\mathrm{Ho}=0.37$ and 0.28 (Aranzana et al., 2002; Dirlewanger et al., 2002)] or apricot (P. armeniaca L.) $[\mathrm{A}=4.10$ and $\mathrm{Ho}=0.51$ (Hormaza, 2002) $]$. The reason why the values given for the cultivated diploid species are generally lower lies in the fact that modern breeding methods in peach and other cultivated species have led to important erosion of the variability. High number of allele per locus and observed heterozygosity indicate that these six markers can be used in black cherry to identify a high level of variation and can therefore be of major potential use in a wide range of studies. For example, they can be used for characterizing and comparing black cherry accessions and helping to determine possible omissions or redundancies in germplasm collections, or be used in comparisons of genetic diversity in populations of the invasive and native ranges.

This study has described the disomic inheritance at six highly polymorphic microsatellite markers, bringing arguments in favor of the allopolyploid origin of black cherry. Those results may explain in part the invasive character and plasticity of the species and enlarge the potential use of these microsatellite markers.

\section{Literature Cited}

Aranzana, M., J. Garcia-Mas, J. Carbo, and P. Arus. 2002. Development and variability analysis of microsatellite markers in peach. Plant Breeding 121:87-92.

Aranzana, M., A. Pineda, P. Cosson, E. Dirlewanger, J. Ascasibar, G. Cipriani, C. Ryder, R. Testolin, A. Abbott, G. King, A. Iezzoni, and P. Arus. 2003. A set of simple-sequence repeat (SSR) markers covering the Prunus genome. Theor. Appl. Genet. 106:819-825.

Ashley, M.V., J.A. Wilk, S.M.N. Styan, K.J. Craft, K.L. Jones, K.A. Feldheim, K.S. Lewers, and T.L. Ashman. 2003. High variability and disomic segregation of microsatellites in the octoploid Fragaria virginiana Mill. (Rosaceae). Theor. Appl. Genet. 107:1201-1207.

Bennett, M.D. 2004. Perspectives on polyploidy in plants - Ancient and neo. Biol. J. Linnean Soc. 82:411-423. 
Bever, J.D. and F. Felber. 1992. The theorical population genetics of autopolyploidy. Oxford Survey Evolutionary Biol. 8:185-217.

Bortiri, E., S.H. Oh, J.G. Jiang, S. Baggett, A. Granger, C. Weeks, M. Buckingham, D. Potter, and D.E. Parfitt. 2001. Phylogeny and systematics of Prunus (Rosaceae) as determined by sequence analysis of ITS and the chloroplast trnL-trnF spacer DNA. Systematic Bot. 26:797-807.

Cantini, C., A. Iezzoni, W. Lamboy, M. Boritzki, and D. Struss. 2001. DNA fingerprinting of tetraploid cherry germplasm using simple sequence repeats. J. Amer. Soc. Hort. Sci. 126:205-209.

Chenuil, A., N. Galtier, and P. Berrebi. 1999. A test of the hypothesis of an autopolyploid vs. allopolyploid origin for a tetraploid lineage: Application to the genus Barbus (Cyprinidae). Heredity 82:373-380.

Cheung, W.Y., N. Hubert, and B.S. Landry. 1993. A simple and rapid DNA microextraction method for plant, animal, and insect suitable for RAPD and other PCR analyses. PCR Methods Applications 3:69-70.

Clarke, J. and R. Tobutt. 2003. Development and characterization of polymorphic microsatellites from Prunus avium 'Napoleon'. Mol. Ecol. Notes 3:578-580.

Decroocq, V., L.S. Hagen, M.G. Fave, J.P. Eyquard, and A. Pierronnet. 2004. Microsatellite markers in the hexaploid Prunus domestica species and parentage lineage of three European plum cultivars using nuclear and chloroplast simple-sequence repeats. Mol. Breeding 13:135-142.

Dewet, J.M.J. 1979. Origins of polyploids, p. 3-17. In: W.H. Lewis (ed.). Polyploidy: Biological relevance. Plenum Press, New York

Dirlewanger, E., P. Cosson, M. Tavaud, M. Aranzana, C. Poizat, A. Zanetto, P. Arus, and F. Laigret. 2002. Development of microsatellite markers in peach (Prunus persica (L.) Batsch) and their use in genetic diversity analysis in peach and sweet cherry (Prunus avium L.). Theor. Appl. Genet. 105:127-138.

Downey, S.L. and A.F. Iezzoni. 2000. Polymorphic DNAmarkers in black cherry (Prunus serotina) are identified using sequences from sweet cherry, peach, and sour cherry. J. Amer. Soc. Hort. Sci. 125:76-80.

Doyle, J.J. and J.L. Doyle. 1990. Isolation of plant DNA from fresh tissue. Focus 12:13-15.

Fowels, H. 1965. Silvics of forest trees of the United States. Agr. Hdbk. 271:539-545.

Godoy, J.A. and P. Jordano. 2001. Seed dispersal by animals: exact identification of source trees with endocarp DNA microsatellites. Mol. Ecol. 10:2275-2283.

Hormaza, J.I. 2002. Molecular characterization and similarity relationships among apricot (Prunus armeniaca L.) genotypes using simple sequences repeats. Theor. Appl. Genet. 104:321-328.

Husch, B. 1954. The regeneration of Prunus serotina in northwestern Pennsylvania following cutting. Ecology 35:11-17.

Lee, S. and J. Wen. 2001. A phylogenetic analysis of Prunus and the Amygdaloideae (Rosaceae) using ITS sequences of nuclear ribosomal DNA. Amer. J. Bot. 88:150-160.

Maynard, C., K. Havanagh, H. Fuernkranz, and A. Draw. 1991. Black cherry (Prunus serotina Ehrh.). Biotechnol. Agr. For. 16:3-22.
Olson, M.S. 1997. Bayesian procedures for discriminating among hypotheses with discrete distributions: Inheritance in the tetraploid Astilbe biternata. Genetics 147:1933-1942.

Powell, W., G. Machray, and J. Provan. 1996. Polymorphism revealed by simple sequence repeat. Trends Plant Sci. 1:215-221.

Ramsey, J. and D.W. Schemske. 2002. Neopolyploidy in flowering plants. Annu. Rev. Ecol. Systematics 33:589-639.

Rehder, A. 1940. Rosaceae Prunus, p.452-481. In: A. Rehder (ed.). Manual of cultivated trees and shrubs: Hardy in North America. Macmillan, New York.

Ronfort, J.L., E. Jenczewski, T. Bataillon, and F. Rousset. 1998. Analysis of population structure in autotetraploid species. Genetics 150:921-930.

Saltonstall, K. 2003. Microsatellite variation within and among North American lineages of Phragmites australis. Mol. Ecol. 12:16891702.

Schueler, S., A. Tusch, M. Schuster, and B. Ziegenhagen. 2003. Characterization of microsatellites in wild and sweet cherry (Prunus avium L.) - Markers for individual identification and reproductive processes. Genome 46:95-102.

Shaw, J. and R.L. Small. 2004. Addressing the "hardest puzzle in American pomology": Phylogeny of Prunus sect. Prunocerasus (Rosaceae) based on seven noncoding chloroplast DNA regions. Amer. J. Bot. 91:985-996.

Soltis, D.E. and P.S. Soltis. 1993. Molecular-data and the dynamic nature of polyploidy. Crit. Rev. Plant Sci. 12:243-273.

Stairs, G. and W. Hauck. 1968. Reproductive cytology of black cherry (Prunus serotina Ehrh.). Proc. 15th NE Tree Improvement Conf. 42-53.

Stebbins, G.L. 1947. Types of polyploids: their classification and significance. Adv. in Genet. 1:403-429.

Stebbins, G.L. 1950. Polyploidy I: Occurrence and nature, p. 298-341. In: L.C. Dunn (ed.). Variation and evolution in plants. Columbia Univ. Press, New York.

Tutin, T.G., V.H. Heywood, N.A. Burges, D.M. Moore, D.H. Valentine, S.M. Walters, and D. Webb. 1968. Flora Europaea (Rosaceae to Umbelliferae). Cambridge Univ. Press, London.

Wilcove, D.S., D. Rothstein, J. Dubow, A. Phillips, and E. Losos. 1998. Quantifying threats to imperiled species in the United States. Bioscience 48:607-615.

Wolf, P.G., P.S. Soltis, and D.E. Soltis. 1989. Tetrasomic inheritance and chromosome pairing behavior in the naturally occurring autotetraploid Heuchera grossulariifolia (Saxifragaceae). Genome 32:655-659.

Wünsch, A. and J. Hormaza. 2002. Molecular characterization of sweet cherry (Prunus avium L.) genotypes using peach (Prunus persica (L.) Batsch) SSR sequences. Heredity 89:56-63.

Yamamoto, T., K. Mochida, T. Imai, Y. Shi, I. Ogiwara, and T. Hayashi. 2002. Microsatellite markers in peach (Prunus persica (L.) Batsch) derived from an enriched genomic and cDNA libraries. Mol. Ecol. Notes 2:298-301. 